\title{
O DESMATAMENTO E O CORONAVÍRUS - UMA DUPLA EPIDEMIA NA AMAZÔNIA
}

\author{
DEFORESTATION AND CORONAVIRUS - A DOUBLE EPIDEMIC IN \\ THE AMAZON
}

\author{
Roger Luiz Paz de Almeida \\ Adriana Lo Presti Mendonça ${ }^{2}$ \\ Leonam da Costa Portela ${ }^{3}$
}

\section{RESUMO}

O estudo consiste na análise documental, bibliográfica e estatística do desmatamento na Amazônia fazendo relação com o novo coronavírus. É possível afirmar que a Amazônia se encontra sob uma dupla epidemia: uma decorrente do surgimento do coronavírus, que se dissemina nas cidades e localidades rurais, aldeias indígenas e quilombolas com maior violência, em razão das faltas de políticas públicas em oferecer infraestrutura e medicamento para os povos ribeirinhos e tradicionais, além da dificuldade de acesso face à logística da região; e a outra, decorrente do desmatamento. A hipótese apresentada consiste na intrínseca relação entre a proliferação do coronavírus e o aumento dos índices de desmatamento na região amazônica. O resultado da pesquisa, segundo textos e estatísticas, consiste na preocupante constatação: a Amazônia encontra-se sob uma dupla epidemia. A opção metodológica envolve uma pesquisa descritiva e de revisão sistemática da literatura, realizada por meio de pesquisa bibliográfica, documental e estatística, com análise dos instrumentos jurídicos, textos normativos, doutrina, jurisprudência e da literatura já publicada em forma de livros, revistas, artigos, publicações avulsas, publicações especializadas, imprensa escrita e dados oficiais publicados na Internet, que abordem direta ou indiretamente o tema em análise. Os estudos mostram que o desmatamento tropical pode fornecer requisitos para novas doenças respiratórias em decorrência do elevado número de queimadas, o que pode levar a um aumento significativo dessas doenças em época de pandemia, devendo-se observar se há uma intrínseca relação entre o desmatamento e o avanço do coronavírus, especialmente no período de verão amazônico.

\section{PALAVRAS-CHAVE:}

Desmatamento; Sustentabilidade; Pandemia; Coronavírus.

\footnotetext{
1 Doutor em Direito pela Pontifícia Universidade Católica do Paraná com estágio sanduíche na Universidade de Barcelona/Espanha. Mestre em Direito pela Universidade do Estado do Amazonas. Magistrado vinculado ao Tribunal de Justiça do Estado do Amazonas. E mail: rogeralmeidax@ gmail.com

2 Mestranda em Constitucionalismo e Direitos na Amazônia. Especialista em Direito Processual Civil pela Universidade Federal do Amazonas. Advogada. E mail: adrianalpmendonca@ hotmail.com.

3 Graduado em Direito pela Universidade Federal do Amazonas-UFAM. Especialista em Direito Público pela Faculdade de Direito Professor Damásio de Jesus-FDDJ. Especialista em Direito Civil e Processual Civil pela Faculdade de Direito Professor Damásio de Jesus-FDDJ. Mestrando em Direito Constitucional pela Universidade Federal do Amazonas-UFAM. Oficial Registrador. E mail: leocp1983@gmail.com.
} 


\begin{abstract}
The study consists of documentary, bibliographic and statistical analysis of deforestation in the Amazon, relating to the new coronavirus. It is possible to affirm that the Amazon is under a double epidemic: one resulting from the emergence of the coronavirus, which spreads in cities and rural locations, indigenous and quilombola villages with greater violence, due to the lack of public policies in offering infrastructure and medicine for riverside and traditional peoples, in addition to the difficulty of access in view of the region's logistics; and the other, due to deforestation. The hypothesis presented consists of the intrinsic relationship between the proliferation of coronavirus and the increase in deforestation rates in the Amazon region. The result of the research, according to texts and statistics, consists of the worrying observation: the Amazon is under a double epidemic. The methodological option involves a descriptive research and systematic review of the literature, carried out through bibliographic, documentary and statistical research, with analysis of the legal instruments, normative texts, doctrine, jurisprudence and the literature already published in the form of books, magazines, articles, individual publications, specialized publications, written press and official data published on the Internet, which address directly or indirectly the subject under analysis. Studies show that tropical deforestation can provide requirements for new respiratory diseases due to the high number of fires, which can lead to a significant increase in these diseases during a pandemic season, and it should be noted whether there is an intrinsic relationship between deforestation and the advancement of coronavirus, especially in the Amazonian summer period.
\end{abstract}

\title{
KEYWORDS:
}

Deforestation; Sustainability; Pandemic; Coronavirus.

\section{INTRODUÇÃO}

No meio da floresta tropical, duas epidemias se alastraram. De um lado o vírus da Covid19 toma conta de sua população e, de outro, o desmatamento avança desenfreado em suas florestas. Manaus, a maior cidade da Amazônia, está em um ponto de ruptura. A Prefeitura mandou cavar valas comuns, ou trincheiras, para enterrar seus mortos e, em razão da pandemia e do afrouxamento da fiscalização, as queimadas se intensificam.

Próxima de se tornar a próxima Guayaquil, Manaus, capital do maior estado brasileiro, em razão da pandemia passou a ser comparada com a cidade portuária do Equador, onde as imagens de corpos não enterrados ainda estão gravadas na mente de muitas pessoas. A Amazônia tem uma das mais altas taxas de infecção do Brasil e também um dos sistemas de saúde mais subfinanciados, uma combinação que trouxe o caos ao coração da selva. 
Em abril de 2020, Manaus registrou um aumento de 578\% no número de pessoas que morreram de problemas respiratórios. Eles não são oficialmente identificados como vítimas da COVID-19, mas os especialistas acreditam que só pode haver uma explicação. Com a baixa quantidade de testes realizados, percebe-se que há uma enorme subnotificação dos números reais, porém mesmo os números oficiais - cerca de 92.000 casos confirmados e mais de 6.500 mortes - levaram o Brasil a atingir um marco sombrio de contaminação e mortes ao passar pela China, onde o surto começou (AMAZONAS, 2020).

No entanto, há outro surto que preocupa: o desmatamento na Amazônia, que já se mostra muito maior do que em 2019. As projeções, com base nos dados dos últimos quatro anos, mostram que a taxa deve estar entre $12.000 \mathrm{~km} 2$ e $16.000 \mathrm{~km} 2$, configurando uma escalada do aumento da destruição da maior floresta tropical da região, comparável apenas aos piores momentos de sua história (ARAGÃO; SILVA JÚNIOR; ANDERSON, 2020).

Infelizmente, com tais estatísticas tem-se que se consolidará o término do longo período de reduções na perda de cobertura florestal ocorrida após a implementação do Plano de Prevenção e Controle do Desmatamento para a Amazônia, lançado em 2004.

Pesquisas mostram que o desmatamento acumulado a partir de agosto de 2019, que irá compor a taxa de 2020, atingiu 5.666,10 km2. Esse número está 94,4\% acima do registrado em abril de 2019 e 83,7\% acima da média dos últimos quatro anos para este mês. Essa taxa, que é excessivamente alta para esse período do ano, será fortemente pressionada por dois fatores. $\mathrm{O}$ primeiro é que o desmatamento mensal medido pelo DETER (Detecção de Desmatamento em Tempo Real) foi muito superior ao observado em todos os meses do ano anterior e superior à média desses meses nos últimos quatro anos (ARAGÃO; SILVA JÚNIOR; ANDERSON, 2020).

O segundo fator, ainda mais preocupante, é que junho é a estação seca na Amazônia, a qual em média dura até outubro, dependendo das variações climáticas de cada ano. Como tem sido o caso desde a implementação do Programa de Monitoramento da Floresta Amazônica Brasileira por Satélite (PRODES) em 1988, os próximos meses registrarão um aumento acelerado do desmatamento e incêndios, facilitado pela redução das chuvas que dificultam as operações no campo (MACHADO-SILVA et al., 2020). 
Diante deste cenário, o risco de doenças respiratórias devido à poluição do ar causada por incêndios pode aumentar o impacto da COVID-19, principalmente para os povos indígenas e ribeirinhos, cujas terras podem estar mais próximas dos desmatamentos e incêndios.

Estudos recentes sugerem uma ligação entre a exposição à poluição das partículas do ar e casos mais graves de coronavírus, assim, somados à recente pandemia, os aumentos sazonais da malária e da dengue na Amazônia durante o verão pressionarão mais regiões remotas onde o sistema de saúde é precário, praticamente inexistindo leitos hospitalares com respiradores e UTIs.

Com o isolamento social e fechamento do comércio impostos pelas autoridades, em razão do novo coronavírus, a economia se arrefeceu e, com todos os olhares voltados para a epidemia, garimpeiros, madeireiros e grileiros aproveitaram a falta de fiscalização e avançaram num desmatamento criminoso da Amazônia.

Para se entender a importância do tema abordado e da necessidade de um olhar para o que está acontecendo, será feita uma breve abordagem sobre os clássicos econômicos e a economia ambiental, bem como da sustentabilidade urbano-ambiental.

Assim, o objetivo deste artigo é mostrar o avanço da doença nos estados da Amazônia, concomitantemente ao aumento do desmatamento, bem como a necessidade de debates e políticas públicas, a fim de se evitar o desmatamento da Amazônia brasileira e a proliferação do novo coronavírus na região, segundo textos e estatísticas.

O resultado da pesquisa, segundo textos e estatísticas, consiste na preocupante constatação: a Amazônia encontra-se sob uma dupla epidemia. Uma decorrente do surgimento do coronavírus. A outra, decorrente do desmatamento, que se dissemina em tempos de epidemia - madeireiros e grileiros aproveitam a falta de fiscalização e avançam em um desmatamento criminoso da Amazônia.

Assim, este trabalho apresenta como hipótese a ser debatida a intrínseca relação entre a proliferação do coronavírus e o aumento dos índices de desmatamento na região amazônica, bem como a necessidade de debates e políticas públicas, a fim de se evitar o desmatamento da Amazônia brasileira e a proliferação do novo coronavírus na região. 
A metodologia escolhida para a consecução dos objetivos da pesquisa é bibliográfica, através da revisão da literatura existente sobre o tema. Seguir-se-á o método de abordagem hipotético-dedutivo, capaz de proporcionar a elaboração de fundamentação jurídica sólida para o alcance do objetivo proposto. Far-se-á, inicialmente, uma abordagem sociojurídica que permita efetuar pesquisas nos aspectos teóricos que envolvem o tema. A opção metodológica envolve uma pesquisa descritiva e de revisão sistemática da literatura, realizada por meio de pesquisa bibliográfica, documental e estatística, com análise dos instrumentos jurídicos, textos normativos, doutrina e jurisprudência.

Buscar-se-á explicar o problema por intermédio da análise da literatura já publicada em forma de livros, revistas, artigos, publicações avulsas, publicações especializadas, imprensa escrita e dados oficiais publicados na Internet, que abordem direta ou indiretamente o tema em análise.

O texto encontra-se organizado em cinco seções, sendo a primeira essa introdução, a qual se segue a análise dos clássicos econômicos e a economia ambiental. Seguidamente, delineia-se, sucintamente, as questões a serem debatidas sobre a sustentabilidade urbanoambiental. Posteriormente, analisa-se o desmatamento na Amazônia brasileira. Por fim, a ênfase será na análise da intrínseca relação entre o desmatamento e a proliferação do coronavírus na Amazônia.

\section{OS CLÁSSICOS ECONÔMICOS E A ECONOMIA AMBIENTAL}

A visão neoclássica é atualmente a visão dos economistas da corrente principal sobre o desenvolvimento sustentável. A teoria neoclássica é baseada na análise marginal. Isso pressupõe que os indivíduos tomem decisões comparando as mudanças na satisfação ou nas receitas com as mudanças no custo. Os recursos naturais não são pontos de vista como restrição à atividade econômica. A sustentabilidade, do ponto de vista neoclássico, pode ser definida como a maximização do bem-estar humano ao longo do tempo, ou seja, promovendo uma visão de alto crescimento. Alguns economistas simplificam isso para a maximização da utilidade derivada do consumo, o que permite uma medição fácil. Essa simplificação, por mais útil que 
tenha sido, foi criticada como uma simplificação excessiva. De um modo geral, em termos dessa abordagem, a natureza e o capital não possuem um valor intrínseco, eles são meros instrumentos usados para alcançar a máxima utilidade. Os economistas neoclássicos não rejeitam completamente a visão de que os recursos naturais não são renováveis, mas acreditam que isso não sugere que o crescimento econômico deva ser limitado.

A economia convencional exclui a natureza como externalidade do processo econômico; a economia ambiental se preocupa em dar preço à natureza, com a tendência de vê-la como amenidade (uma ideia implícita na noção vulgar do "verde"); e a economia ecológica atribui à natureza a condição de suporte insubstituível de tudo o que a sociedade pode fazer. A visão econômica tradicional inclui não só o pensamento da economia neoclássica de Hayek, Milton Friedman, Robert Solow e seus seguidores (no Brasil, nome ilustre é o de Mário Henrique Simonsen), como também o dos keynesianos, marxistas, institucionalistas, estruturalistas, monetaristas, economistas políticos: um verdadeiro pensamento único (CAVALCANTI, 2010, p. $63)$.

Conforme Montibeller et al. (2012), o desenvolvimento sustentável como um reflexo das sociedades deseja ter um bem-estar não declinante com o tempo. Portanto, é importante assegurar que as taxas de poupança sejam suficientemente altas para garantir que o estoque de capital disponível permaneça constante entre as gerações. A escola neoclássica de pensamento baseia-se em quatro pressupostos fundamentais:

- Os preços de mercado são indicadores de escassez, o sistema de mercado é eficaz e a informação é transmitida rapidamente;

- Recursos possuem altas taxas de substituição;

- A evolução tecnológica melhora a escassez de recursos;

- A economia humana pode ser tratada separadamente dos ecossistemas naturais, que por sua vez são determinados exogenamente.

Os recursos ambientais são valorizados em termos de preferência do consumidor. Isso, por sua vez, é refletido pelo sistema de mercado. Acredita-se que os mercados ajustam automaticamente a escassez através do sistema de preços, assim, como um recurso se torna mais escasso, seu preço de fator sempre responderá à escassez aguda e o aumento de preço correspondente induzirá o desenvolvimento de mecanismos para prolongar o uso de fatores, bem como alternativas (tecnologias de recuo). Desta forma, presume-se que o sistema de preços valorize efetivamente os vários capitais de recursos que, por sua vez, devem gerar a taxa de 
substituição entre recursos. Os neoclássicos reconhecem a existência de externalidades no mercado, mas acham que pequenos ajustes serão responsáveis por esses fatores (VATN, 2016).

Uma suposição fundamental da abordagem neoclássica é a visão de que o capital natural e o capital criado são substitutos perfeitos. O capital natural pode ser definido como todos os recursos renováveis e não renováveis, como combustíveis fósseis, espécies de plantas e florestas. O capital manufaturado, também conhecido como capital social ou capital criado, é composto por todos os produtos, sejam máquinas ou ferramentas utilizadas no processo econômico. Essa forma de capital pode ser gerada a partir do capital natural, do capital manufaturado ou de uma combinação dos dois, sendo que ambas as formas de capital compreendem o capital total.

Solow (1974 apud MAY, 2010), em seu modelo que determina as condições sob as quais o crescimento contínuo de uma economia seria possível, traz que o conceito de recursos finitos não amorteceu a existência de crescimento indefinido e, além disso, ele sentiu que as gerações atuais poderiam utilizar esses recursos finitos, desde que adicionados ao estoque de capital manufaturado, portanto, com uma alta substituibilidade do capital natural por capital criado, o estoque total de capital pode aumentar constantemente sem fim.

De acordo com Montibbeler et al. (2012), no método de Cobb-Douglas, essa elasticidade unitária levará a uma produtividade marginal e média crescente do capital, mesmo quando a relação entre capital natural e capital produzido tender para zero. Esta propriedade de substituição é um dos principais requisitos subjacentes da maioria dos modelos neoclássicos, incluindo o de Solow em 1974. Em suas obras, Robert Solow identifica que uma troca ocorre ao longo do tempo onde a geração atual usa mais do capital natural e em troca fornece mais, criou capital para as futuras gerações.

Uma das suposições do método de Cobb-Douglas, que constituiu a base da regra de Hartwick (1977), é que a taxa de desenvolvimento técnico deve ser relativamente alta em relação à taxa de crescimento populacional e à participação total do capital natural. Os aluguéis gerados pelo uso de recursos naturais não renováveis devem ser reinvestidos no capital técnico, permitindo uma transferência crescente, ou pelo menos constante, do capital ao longo do tempo. Essa abordagem considera a sustentabilidade como o restante do capital constante ao 
longo do tempo, independentemente da proporção do capital criado para o capital natural (VATN, 2016).

A tecnologia possui um papel importante para a teoria neoclássica. A tecnologia pode ser definida como a maneira pela qual as entradas são usadas para gerar saídas, portanto, as inovações tecnológicas são a geração constante de resultados usando menos entradas. A suposição de perfeita substituibilidade entre formas de capital elimina o problema da disponibilidade de recursos dentro de uma economia. Diz-se que a tecnologia não tem limitações para a melhoria da escassez de recursos naturais (ANDRADE, 2008).

O autor supracitado menciona ainda que a visão neoclássica do meio ambiente é estritamente antropogênica, ou seja, causado pela ação do homem. Observa-se que a valorização do meio ambiente é feita com base na utilidade adquirida, e o papel ecológico mais amplo dos recursos naturais não é considerado em seu valor econômico. Desta forma, é a visão das teorias econômicas neoclássicas que cálculos contábeis nacionais convencionais, como o produto interno bruto (PIB), revelam a riqueza de uma nação. Essas contas econômicas nacionais registram fluxos monetários e transações dentro da economia, mas também sinalizam bem-estar humano ou desenvolvimento. A contribuição da natureza para o processo de produção é ignorada nesses cálculos. Portanto, a sustentabilidade é, em essência, vista pelos economistas neoclássicos como um problema de gestão do portfólio nacional de capital, mantendo-o em um nível fixo. Pearce e Atkinson (1993, apud VATN, 2016) formaram um índice de sustentabilidade para indicar o nível de DS ocorrido. Esse índice pode ser definido como a diferença entre a taxa de poupança e a taxa de depreciação geral do capital natural e manufaturado.

A faceta final da teoria neoclássica que será analisada é o desconto. Esta é uma ferramenta usada para avaliar o valor do dinheiro no tempo. Descontar reflete os desejos das pessoas de avaliar os prazos atuais mais do que o futuro distante. $\mathrm{O}$ desconto é um processo apropriado de acordo com a teoria neoclássica, pois reflete as preferências das pessoas. Para maximizar sua utilidade, os custos de oportunidade do investimento precisam ser pesados. Nesse sentido, o desconto é tratado como racional, otimizando o comportamento humano (ANDRADE, 2008). 
Entre internalização de lucros e externalização de custos, depara-se com uma sociedade que se preocupa com um crescimento indefinido da economia, diante da insistência no aumento permanente do consumo de bens e serviços, sem se importar com a degradação ambiental ou o deslocamento de populações, levando a um colapso o sistema suporte da vida.

\section{SUSTENTABILIDADE URBANO-AMBIENTAL: QUESTÕES A SEREM DEBATIDAS}

Reestruturação econômica, transformação sociopolítica, tecnologia, inovação e redes globais tiveram um profundo impacto sobre a posição das cidades e regiões no mundo todo, principalmente após a pandemia que causou não só impactos na saúde, na economia, mas também no meio ambiente.

Isso também vale para cidades de países em desenvolvimento. Eles enfrentam a urgência e a necessidade de resolver problemas de pobreza, moradia e desemprego e, ao mesmo tempo, também enfrentam a necessidade de gerar competitividade para ser sustentável e sobreviver à feroz concorrência nacional e internacional. No contexto da competição e ganhos ou perdas no comércio (de bens e serviços), a ideia de desenvolvimento sustentável está cada vez mais em evidência (MARQUES, 2009).

A noção de 'desenvolvimento sustentável' (DS) foi discutida extensivamente nos últimos anos, entretanto, essas discussões muitas vezes consideram a sustentabilidade em escala global e, em grande parte, têm focado em questões conceituais. Consequentemente, não surpreende que a falta de aplicabilidade empírica em um contexto político concreto seja uma das principais fontes de críticas. Um tratamento mais operacional deste conceito abstrato de DS parece ser a única maneira de sobreviver no debate atual sobre o nosso futuro comum, como foi enfatizado na Conferência das Nações Unidas sobre Meio Ambiente e Desenvolvimento, também conhecida como Eco-92, realizada no Rio de Janeiro em 1992.

O DS foi definido como um padrão de desenvolvimento que atende às necessidades das gerações presentes sem pôr em risco a capacidade de gerações para atender às suas próprias 
necessidades. Dentro do contexto do presente artigo, isso pode ser interpretado de modo que o desenvolvimento econômico deve ocorrer de forma a deixar intacta sua base de recursos, a fim de oferecer às gerações futuras um acesso igual às possibilidades de uso do ambiente natural como insumo para o processo de geração de bem-estar. Essa base de recursos refere-se a dois elementos: (i) recursos próprios, ou seja, o total de todos os aspectos ambientais relevantes em estoques (como pesca, florestas, terras aráveis, água, qualidade do ar e etc.; e (ii) a 'infraestrutura ambiental', isto é, os processos ambientais e os sistemas de suporte à vida (por exemplo, processos de regeneração de recursos e sistemas de absorção de resíduos) (CONSTANTINO, 2019).

O DS não apenas possui uma dimensão intergeracional, mas também contém outros aspectos, de caráter alocativos espaciais. Tais dimensões espaciais variam de global a local. Exemplos globais incluem aumento do nível dos oceanos, causado principalmente pelo aquecimento global ou clima alterado; destruição da camada de ozônio; desmatamento; desertificação; e extinção de espécies. Exemplos locais dizem respeito, por exemplo, à poluição em áreas que enfrentam forte desenvolvimento urbano; riscos de produtos químicos, indústrias tóxicas nuclear e radioativa; construção de estrada; e catástrofes locais. Um atributo comum desses exemplos é que eles ameaçam a sobrevivência humana e ambiental e, portanto, são mudanças "negativas" ou "indesejáveis" que alguém deve tentar evitar ou enfrentar. Mudanças 'Positivas' (regeneração de estoques ambientais naturais, avanços na tecnologia ambiental e assim por diante) são, por definição, 'bem-vindas' (CONSTANTINO, 2019).

É necessária uma ação científica intensificada para apoiar e aprimorar essas mudanças 'positivas'. Uma análise de DS operacionalmente relevante deve oferecer diretrizes concretas e viáveis para o conteúdo e as medidas a serem tomadas a fim de cumprir o objetivo do DS.

De acordo com Marques (2009), dentro desse contexto geral, ferramentas devem ser desenvolvidas para analisar e gerenciar processos econômicos em nível local. A lógica inerente de uma análise de desenvolvimento sustentável local (DSL) decorre da crença de que esse estudo pode tornar, no nível local, as interdependências funcionais mais gerenciáveis, tendo em vista o processo contínuo de desenvolvimento das cidades e regiões. De uma gerência e ponto de vista político, o nível local é mais adequado para o controle e transformação do que a escala global. Desta forma, é evidente que o objetivo do DS pode ser alcançado mais facilmente se os 
processos de desenvolvimento socioeconômico e mudança ambiental em escala local forem mais claramente entendidos e adequadamente gerenciados.

Infelizmente, em razão da ausência de políticas públicas, investimentos e fiscalização, o desenvolvimento sustentável local não tem acontecido na Amazônia da forma que deveria, levando madeireiros e grileiros a explorarem de forma ilegal a floresta, causando queimadas, desmatamentos e, consequentemente a degradação ambiental.

\section{DESMATAMENTO DA AMAZÔNIA BRASILEIRA}

A maior parte do mundo luta contra o desmatamento da Amazônia há quase 30 anos. A indústria de madeira pouco ofereceu em face da preocupação mundial de que danos permanentes estão sendo causados ao meio ambiente. O Amazonas, que é o maior estado do Brasil, compondo a maior parte noroeste do país, e embora seja o maior estado da nação, é também o menos povoado. A maioria da população pode ser encontrada vivendo em meia dúzia de cidades, e se concentra ao longo do rio Amazonas. A população indígena, que costumava constituir uma parte significativa da população do país, continua a desaparecer devido a doenças, desmatamento e deslocamento econômico. O Amazonas é composto quase inteiramente de floresta tropical, estimando-se que do total, $95 \%$ das terras do estado sejam compostas por esse bioma, o que significa que existem cerca de 350 milhões de hectares de floresta tropical nessa região do país. Outros 700 milhões de hectares de floresta tropical encontram-se nas nações vizinhas, mas nada comparável ao presente no Brasil (BRASIL, 2019).

As florestas tropicais exercem uma grande influência no clima e afetam as taxas de troca de energia entre a atmosfera e a superfície da Terra, elas também absorvem dióxido de carbono, e são um elemento importante na progressão do ciclo da água. O desmatamento tem um efeito dramático no meio ambiente e prejudica o futuro desenvolvimento ecológico da terra. Assim, a necessidade de preservar florestas é uma condição necessária para a preservação, em longo prazo, da vida humana, e é a base do movimento conservacionista. Infelizmente, o futuro do meio ambiente não é a única preocupação da maioria dos países, posto que as questões 
econômicas obscurecem grande parte das considerações éticas e razoáveis quando as nações buscam seus melhores interesses. Torna-se quase impossível para as nações almejadas pelo crescimento econômico, colocar o bem-estar do meio ambiente global diante de sua própria estabilidade econômica e política (ARRAES; MARIANO; SIMONASSI, 2012).

O Amazonas é a principal fonte de madeira para o mundo, seguida pelo Congo, sendo os Estados Unidos, Grã-Bretanha, Canadá e Japão os quatro maiores compradores estrangeiros de madeira e produtos de madeira brasileiros. O governo brasileiro está plenamente consciente da importância da floresta amazônica e, na última década, tomou várias medidas para diminuir a quantidade de floresta tropical destruída para a produção de madeira. O Brasil também estabeleceu muitas novas leis proibindo e punindo empresas que cortam madeira rara tais como mogno e virola, tendo, também, reduzido os subsídios ao setor agrícola que havia trabalhado no Amazonas. Com uma preocupação dos Governos atuais voltada mais para a crescente dívida nacional e desvalorização da moeda, a preocupação com o desmatamento e a violação dos recursos naturais parece estar em segundo plano.

Nos últimos anos, a agricultura em larga escala experimentou uma expansão considerável e se tornou o mais novo fator de desmatamento na região. O Brasil é um dos maiores produtores e exportadores mundiais de cana-de-açúcar, soja, laranja e outros produtos. Nos nove estados da Amazônia brasileira, a área sob intensa agricultura mecanizada cresceu mais de 3,6 milhões de hectares de 2011 a 2014. Particularmente durante esse período, o maior aumento na área plantada com soja foi no Mato Grosso, o estado brasileiro com a maior taxa de desmatamento (40\% do novo desmatamento). Ao deslocar os pecuaristas, a produção de soja empurrou a fronteira do desmatamento da Amazônia para o norte. Entre 2011 e 2014, a área desmatada para terras cultiváveis e o preço médio anual da soja no ano do desmatamento foram diretamente correlacionadas. As forças que impulsionam a expansão da agricultura mecanizada incluem custos mais baixos de transporte como resultado da melhoria da infraestrutura local (estradas, ferrovias, portos e hidrovias); preços internacionais mais altos da soja; aumento da demanda de soja nos mercados europeus devido à doença da vaca louca (encefalopatia espongiforme bovina); e rápido crescimento econômico na China (9\% ao ano), que consome grandes quantidades de aves e suínos alimentados com soja (BRASIL, 2019).

A soja também pode ser usada para biocombustível. O governo brasileiro declarou a adição obrigatória de 2\% de biocombustível ao diesel de petróleo a partir de 2008. Em 2013, a 
proporção aumentou para 8\%, o que elevou o consumo de biocombustível para 2,5 milhões de litros por ano. Essa política, juntamente com o interesse anunciado de outros países em combustíveis alternativos, incentivou os produtores locais a aumentar sua área de plantio de soja. Seriam necessários cerca de 2 milhões de hectares apenas para atender à nova demanda brasileira. Além disso, o Brasil adquiriu conhecimento tecnológico na produção de etanol a partir da cana-de-açúcar (SOUZA et al., 2020).

Embora o aumento da demanda por soja e o crescimento de biocombustíveis represente excelentes oportunidades para o Brasil, o desafio é aumentar a produção sem incentivar novos desmatamentos. O Ministério da Agricultura afirma que a área total de terras já desmatadas e aráveis no Brasil é mais que suficiente para aumentar as plantações de soja sem a necessidade de mais desmatamentos. Por exemplo, a produção nacional de etanol poderia ser dobrada usando apenas 3,3\% dos 90 milhões de hectares de terras aráveis do Brasil. No entanto, é preciso tomar cuidado para evitar novos desmatamentos causados pelo deslocamento de outras atividades econômicas, como a pecuária, que já ocorreu. Quando os biocombustíveis aumentam a demanda por culturas, proporcionalmente os preços são elevados, as fazendas se expandem e os fazendeiros deslocados limpam novas terras, geralmente em áreas de floresta onde os preços da terra ainda são baixos. A nova ocupação de áreas, que antes eram remotas e associadas a problemas de presença governamental e posse da terra, tende a ser caótica (SOUZA et al., 2020).

O agronegócio tem sido uma das forças mais fortes para a implementação de novas infraestruturas na região, especialmente estradas. $\mathrm{O}$ atual plano de infraestrutura governamental para a Amazônia inclui pavimentação de estradas, novos projetos hidrelétricos e construção de hidrovias e portos. Tem o potencial de mudar drasticamente a situação social, econômica e ambiental da Amazônia. As estradas pavimentadas podem gerar benefícios econômicos e sociais, mas também o desmatamento e a degradação florestal, se não forem acompanhadas pelo planejamento regional. Estudos mostraram que mais de $70 \%$ do desmatamento ocorre a 50 $\mathrm{km}$ de estradas pavimentadas, enquanto no máximo 7\% ocorre ao longo de estradas não pavimentadas. A promessa de uma nova rodovia (Br-163) na Amazônia central já levou muitas novas serrarias para a região e redirecionou a migração (IPAM, 2020).

O desmatamento facilitado pela pavimentação de estradas e a falta de fiscalização das leis também pode aumentar drasticamente as emissões líquidas anuais de carbono da Amazônia. 
O modelo prevê que, no cenário de negócios usuais, 32 bilhões de toneladas de carbono seriam emitidas até 2050 (equivalente a quatro anos das atuais emissões anuais globais), em contraste com 15 bilhões de toneladas de carbono no cenário de governança.

Soares-Filho et al. (2006) também analisaram a potencial perda de espécies nesses dois cenários. Em 2050, cerca de 100 espécies de mamíferos (30\%) perderiam mais de 40\% das florestas dentro de suas faixas de distribuição no cenário normal, em comparação com 39 espécies $(10 \%)$ no cenário de governança.

As áreas protegidas assumem um papel importante na conservação da floresta e da biodiversidade, por exemplo, quase $40 \%$ das faixas de distribuição de mamíferos estão dentro de áreas protegidas. Os impactos das estradas seriam sentidos em 89 terras indígenas, 22 áreas protegidas e 68 áreas prioritárias para a conservação da biodiversidade - em 28\% das áreas protegidas em geral (IPAM, 2020). A análise de Soares-Filho et al. (2006) mostraram que, em um cenário de negócios como de costume, as áreas protegidas fariam pouco sozinhas, contribuindo para a redução do novo desmatamento para $7 \%$ abaixo da linha de base de negócios como de costume. Por outro lado, as áreas protegidas associadas a um cenário de governança poderiam evitar um terço do desmatamento projetado para ocorrer em 2050 no cenário de negócios usuais.

No passado, os agricultores eram pouco instruídos e não tinham acesso a técnicas de cultivo tais como rotação de culturas e reabastecimento do solo. A maioria dos agricultores até hoje faz o manejo de algodão ou tabaco, porque ambos são mais aceitos no agronegócio. Com efeito, a exportação exige um uso maior do solo, sendo prejudicial para a terra esgotando seus nutrientes. Tal prática, nesse contexto, força os agricultores a degradar novas terras adentrando ainda mais nas florestas em busca de solo rico e fértil, sendo inegável que esta conjuntura apresenta um custo social premente que poderia ser mitigado à medida que governos ou grupos do setor privado se deslocassem para países do terceiro mundo, assumindo a responsabilidade de ensinar aos agricultores maneiras mais econômicas e ecologicamente mais sólidas de cultivar as terras. Grupos do setor privado que chegam a países do terceiro mundo também possuem a capacidade de ajudar a estabelecer mercados para as culturas e criar um meio para os agricultores venderem outros tipos de culturas além do algodão e do tabaco. A ideia seria melhorar a vida dos agricultores e, ao fazê-lo, alistá-los na batalha para salvar as florestas tropicais (MOUTINHO, 2019). 
De acordo ainda com o autor supracitado, a maneira mais viável de educar os agricultores viria do financiamento do governo local ou da concessão de incentivos fiscais para grupos do setor privado que entrassem no país. Esse processo educacional precisaria ser de longo prazo e direcionado a grupos mais próximos da floresta tropical. Muitas tentativas foram feitas para educar os agricultores, mas a maioria delas restou-se infrutíferas, pois, não tinham a consistência e a amplitude necessária para instruir os povos ali envolvidos a utilizarem a agricultura com diversos tipos de cultura.

Segundo os estudos de Ellwanger et al. (2020), muitos países consideram as florestas tropicais como um recurso natural valioso, considerando-se bens negociáveis para aumentar a renda nacional e, segundo a estimativa de preço nesses países, a floresta tropical varia de 1 bilhão de dólares por milhão de hectares a 4 bilhões de dólares por milhão de hectares, dependendo da densidade da floresta tropical e da quantidade de madeira rara na área especificada. Não é errado que os governos desejem desenvolver a terra para ajudar sua nação, mas é irrazoável que eles vendam voluntariamente mais terras voltadas para a degradação.

Os autores supramencionados destacam ainda que esses governos que pretendem vender florestas com fins lucrativos precisam seguir pelo menos algumas diretrizes razoáveis. Ellwanger et al. (2020) pontuam as seguintes orientações:

1) Designar partes das florestas para parques nacionais, extração de madeira industrial, agricultura agrícola e porções para necessidades ainda não vistas.

2) Manter a integridade ecológica das áreas florestais, em parte preservando a diversidade biológica, a água e os ciclos de nutrientes.

3) Maximizar as receitas da floresta na medida em que isso seja compatível com as duas primeiras estipulações.

4) Delinear claramente os direitos e responsabilidades sobre a terra e os recursos, a fim de tornar a distribuição dos benefícios da posse da floresta e usar mais equitativamente.

5) Atrair e incentivar investidores e empresas estrangeiras e locais confiáveis.

6) Tornar a administração da floresta mais eficiente e aberta ao escrutínio público. 
Essas diretrizes ajudariam os países a lidar com a indústria madeireira equilibrando a conservação das florestas e o crescimento econômico da nação. Os governos locais teriam, ainda, que restringir normas permissivas para a indústria madeireira, da seguinte forma: as empresas madeireiras pagariam uma taxa fixa pela entrada nas florestas e receberiam uma área específica de terra, assim estariam mais dispostas a explorar uma delimitada área para maximizar seu lucro, sob pena de multa aplicada pelo governo. Esses títulos poderiam ser comprados pelas empresas madeireiras e, caso negligenciassem as restrições impostas a eles, esse título poderia ser recuperado pelo governo e revendido a outra empresa madeireira.

Para Moutinho (2019), uma das alternativas mais rentáveis e ecologicamente corretas ao desmatamento em massa na Amazônia é atrair não apenas empresas madeireiras responsáveis, mas também incentivá-las a construir instalações de produção dentro dos países dos quais estão explorando. A maior parte da indústria madeireira reduz a madeira e a envia imediatamente para países estrangeiros, onde suas fábricas processam a matéria-prima e outros produtos de madeira. A primeira razão para isso é que grande parte do lucro das empresas madeireiras provém de madeiras raras ou proibidas. Enviando as madeiras para fora do país, as empresas madeireiras podem vendê-las a terceiros e depois encaminhar os produtos acabados para o mercado dos EUA e Canadá com menos problemas dos governos e grupos de conservação. A maioria das nações de onde essas madeiras são exportadas possui leis estritas contra a exportação e a mineração de madeiras raras, como o mogno. Portanto, ao vender a madeira a terceiros, a indústria madeireira é capaz de contornar muitos dos grupos de conservação que buscam a conservação de madeiras raras.

Os governos locais podem ser um grande impedimento para essas empresas se começarem a aplicar penalidades mais duras pela exportação de madeiras raras ou limitarem a quantidade de madeira bruta que pode ser exportada do país. Também oferecendo incentivos fiscais para empresas dispostas a se mudar para o país e montando fábricas para acabamento de produtos madeireiros, as empresas madeireiras estariam mais dispostas a permanecer no país e a não procurar terceiros para vender a madeira (MOUTINHO, 2019).

Grande quantidade de serrarias e fábricas de produção de celulose moderadas custa entre 10 e 20 milhões de dólares e empregaria entre 500 e 2000 nativos. A maioria dos incentivos fiscais do governo é concedida por um período de 10 ou 15 anos e beneficiaria qualquer empresa que pretenda maximizar seus lucros nos próximos anos. Isso também beneficiaria muitos países 
que estavam em processo de industrialização, porque uma das principais razões para o desmatamento em massa na Amazônia é o nível de pobreza e as taxas de desemprego. Essas novas fábricas atrairiam trabalhadores, e não custaria mais mão-de-obra às empresas madeireiras do que pagariam pelas taxas de produção de terceiros (ELLWANGER et al., 2020).

Viana, Freitas e Giatti (2016) assinalam que outro meio muito adequado para diminuir as taxas de desmatamento na Amazônia é acompanhar mais de perto a exportação de madeira e de terceiros que estão tratando e processando as madeiras. Segundo Sauer e Almeida (2011), a maioria dos governos locais precisa urgentemente de um fluxo de caixa e, de bom grado, recebe qualquer ajuda econômica que as empresas madeireiras ofereçam, e por isso muitas vezes voltam às costas a exportação de madeira rara, não sendo necessariamente culpa dos governos, mas de sua responsabilidade, da indústria madeireira e das empresas consumidoras garantir que as madeiras exportadas do país sejam rastreadas e marcadas de acordo com um esquema global. Dessa forma, todas as madeiras poderiam ser rastreadas e os consumidores teriam a capacidade de escolher quais tipos de madeira eles preferem. Isso também seria um bom mecanismo nas mãos dos grupos de conservação, porque eles seriam capazes de notificar consumidores e empresas sobre atividades ilegais das madeireiras.

Não é razoável pensar que as multas e permissões econômicas sejam suficientes para parar o desmatamento na Amazônia, mas são meios pelos quais podemos retardar a destruição da floresta tropical. Entretanto, esses impedimentos econômicos nada mais são do que um impedimento e não uma força preventiva. Ideias como essas, bem como a educação continuada de agricultores nativos ajudarão a preservar as florestas tropicais por pelo menos um curto período de tempo. Durante esse período de desmatamento lento, há esperança de que um meio não destrutivo de colher os recursos naturais de um país possa ser economicamente pesquisado e testado. As soluções relacionadas a salvar as florestas também são extremamente benéficas para as nações que estão sendo desmatadas, porque em quase todas as ideias modeladas esses países também obtêm uma renda mais substancial, educam a população, assim como fornecem industrialização e empregos para os nativos (SAUER; ALMEIDA, 2011).

Os resultados dos estudos de Moutinho et al. (2020) sugerem que entre janeiro de 2019 e abril de 2020, 45\% da área desmatada, que representa $4.509 \mathrm{~km} 2$, equivalente a três vezes o tamanho da cidade de São Paulo, provavelmente será queimado em 2020. Quatro estados (Pará, Mato Grosso, Rondônia e Amazonas) concentram cerca de $88 \%$ desta área, esperando a queima. 
Este processo pode ocorrer a partir do final de junho, quando a estação seca começa na região, período em que as florestas públicas não estatais estaduais e federais são afetadas.

Existe um risco de que a estação seca de 2020 será marcada por incêndios significativos, pelo menos comparáveis aos que ocorreram em 2019 (SILVÉRIO et al., 2019), e se essas previsões estiverem corretas, será uma produção de grandes quantidades de fumaça carregada de partículas finas, afetando a saúde das pessoas (ARAGÃO et al., 2020).

Neste ínterim, em 2019, incêndios na Amazônia foram manchetes internacionais quando ONGs, grupos de direitos humanos e líderes empresariais e políticos pediram boicotes a empresas e produtos brasileiros, o que levou o presidente Bolsonaro a mobilizar o exército para ajudar nos esforços de combate a incêndios, muito embora o Poder Executivo continue empreendendo políticas não sustentáveis (ELLWANGER et al., 2020).

Os estudos de Ellwanger et al. (2020) e Aragão et al. (2020) alertam que todo o bioma pode estar chegando a um ponto crítico, onde grandes áreas de floresta úmida podem fazer a transição para secar florestas e savanas tropicais. Novas pesquisas dizem que a Amazônia pode se transformar em uma fonte de carbono em vez de um dos maiores absorvedores de gás já na próxima década, como resultado dos danos causados pelo aumento do desmatamento na Amazônia, madeireiros ilegais e pela crise climática.

\section{DESMATAMENTO E A PROLIFERAÇÃO DO CORONAVÍRUS NA AMAZÔNIA: UMA INTRÍNSECA RELAÇÃO}

O desmatamento na Amazônia brasileira atingiu um novo recorde nos quatro primeiros meses de 2020, segundo dados divulgados pelo Instituto Nacional de Pesquisas Espaciais (INPE), um centro de pesquisa científica que monitora a floresta por imagens de satélite. Um indicador preocupante, já que, normalmente, não é o período de cortar árvores por causa da estação das chuvas. De janeiro a final de abril, nada menos que $1.200 \mathrm{~km}^{2}$ de floresta desapareceram. Isso representa um aumento de $55 \%$ em relação ao mesmo período do ano passado, o maior desde 2015, quando foram feitas as primeiras observações mensais. 
Ao mesmo tempo em que a pandemia de coronavírus diminuiu a economia global, o desmatamento na Amazônia acelerou. Enquanto a maioria das grandes empresas do Brasil permanece fechada sob medidas de bloqueio e quarentena, madeireiros e mineradores ilegais continuam a operar na área com pouca ou nenhuma fiscalização.

O Brasil tem um dos piores surtos de Covid-19 do mundo, com quase um milhão de casos até as últimas atualizações, o país perde apenas para os Estados Unidos.

Todos os anos, na Amazônia, a fumaça oriunda das queimadas envia um grande número de pessoas aos hospitais, procurando tratamento para problemas respiratórios (BARCELLOS et al., 2019; MACHADO-SILVA et al., 2020). O aumento na suspensão de partículas finas afeta, principalmente, a saúde de crianças e idosos que vivem na região. Durante esse período, algumas cidades permaneceriam por semanas sob uma densa camada de ar poluído, como foi o caso da localidade de Rio Branco e outras cidades do estado de São Paulo e Acre, em agosto de 2019 (MELO et al., 2020).

Esse cenário pessimista de saúde pública pode ser bastante agravado, ao considerar a pandemia da COVID-19. O número de habitantes da Amazônia afetados pelo novo coronavírus está crescendo. Até o final de maio de 2020, havia no país 29.314 mortes, $20 \%$ das quais ocorreram no Norte. A região tem a maior taxa de incidência $(584,6)$ e mortalidade $(30,9)$ por 100 mil habitantes e 107.752 casos confirmados ou $20 \%$ dos casos do total nacional (BRASIL, 2020).

Duas preocupações devem ser destacadas: o avanço do novo coronavírus entre populações indígenas. Até maio do referido ano, houve 731 casos confirmados, 169 suspeitos e 116 mortes por COVID-19, entre os 51 povos indígenas da Amazônia brasileira. Pequenas cidades já mostraram crescimento significativo no número de infectados, que é o chamado Movimento de "internalização" da infecção (ARAGÃO et al., 2020) levando a um colapso na saúde do Estado e ao desmatamento desenfreado com uma fiscalização cada vez mais afrouxada e deficitária.

As comunidades indígenas que vivem na região amazônica foram especialmente afetadas pelo vírus, com uma taxa de mortalidade duas vezes superior ao restante da população, 
de acordo com a Articulação dos Povos Indígenas do Brasil (APIB), grupo de defesa que vem acompanhando casos e mortes entre povos indígenas no Brasil (COIAB, 2020).

Este ano, o risco de doenças respiratórias devido à poluição do ar causada por incêndios pode exacerbar o impacto da Covid-19, principalmente para povos indígenas cujas terras podem estar mais próximas dos incêndios.

Diante dessa situação, mais de 3.000 soldados das Forças Armadas brasileiras foram enviados para a Amazônia, juntamente com autoridades ambientais, com o intuito de ajudar na contenção da extração ilegal de madeira e outras atividades criminosas que poderiam impactar a floresta, segundo o Ministério da Defesa.

Em 2019, depois que incêndios em massa consumiram grandes áreas da floresta tropical, o Governo Federal foi acusado de incentivar a atividade de fazendeiros, mineiros e madeireiros ilegais, muitos dos quais usam o fogo como uma maneira rápida de cortar árvores para abrir espaço para lavouras e pastagens. Em novembro de 2019, a taxa de desmatamento na Amazônia havia atingido seu nível mais alto em mais de uma década.

Uma das providências que o Governo adotou para o momento foi a edição da Medida Provisória 910 (MP 910), uma norma que pode permitir que os chamados "grileiros", que invadiram ilegalmente terras públicas de 2011 a 2018, estabeleçam propriedade legal.

A Presidência da República frequentemente critica a quantidade excessiva de terras amazônicas oficialmente demarcadas como território indígena, tendo, durante um evento no palácio presidencial do Planalto, em Brasília, em fevereiro de 2020, dito que era "abusivo" que uma porção tão grande do território fosse ocupada pelas tribos regionais, deixando "seus bens escondidos para sempre".

Cerca de $13 \%$ do Brasil são terras indígenas, principalmente na Amazônia, sendo que essas terras são oficialmente reservadas para os 900.000 povos indígenas do país, o que representa menos de $0,5 \%$ da população do país (COIAB, 2020).

A Amazônia brasileira poderá, em breve, ser atingida por uma "tempestade perfeita". Uma eventual interação entre a pandemia de COVID-19 e o aumento do desmatamento, seguido de fogo, terá o potencial de causar mais mortes na região. A estação seca e ardente, que começou 
no final de junho, pode ser igual ou ainda mais intensa do que aquela que atingiu a região em 2019 (ALENCAR et al., 2019).

Essa previsão deriva de dois fatores. O primeiro está relacionado ao crescimento sustentado do desmatamento. Uma parte do que foi desmatado no ano passado não foi queimado, devido a ações de combate realizadas pelo governo federal e estadual. Como resultado, há uma vasta extensão de terra coberta de árvores mortas e secas, esperando a seca que se aproxima para ser queimada. O segundo fator deriva do primeiro. E se toda a área calculada e detalhada for queimada, a fumaça atingirá uma população já vulnerável ao novo coronavírus, que causa um grave problema de síndrome respiratória, e que levou milhares de mortes no Brasil (ARAGÃO et al., 2020).

Essa combinação nefasta resultou em um fardo sem precedentes sobre o sistema de saúde já frágil e deficiente na Amazônia, especialmente em cidades menores e distantes dos centros urbanos mais significativos. Portanto, é urgente para o governo e instituições públicas promoverem ações estruturadas para combater o desmatamento e, principalmente, a queima da mata nativa. Com efeito, o foco deve ser dado onde há um acúmulo de áreas desmatadas e não queimadas, entre janeiro de 2019 e abril de 2020 (ARAGÃO et al., 2020).

Sob os efeitos da pandemia, a exposição à fumaça ou exposição ao ar com partículas finas (PM 2.5), resultante de incêndios, pode aumentar a predisposição à infecção pelo coronavírus. De acordo com um estudo recente, o aumento de apenas $1 \mu \mathrm{g} / \mathrm{m} 3$ de partículas (PM 2.5) no ar está associado a um aumento de $8 \%$ na taxa de mortalidade devido a COVID19 (WU et al., 2020). Um aumento na demanda usual por tratamentos para doenças respiratórias pode colocar pressão ainda maior em um sistema de saúde que já registrou um colapso.

É essencial mencionar que, no estado de Amazonas, somente a cidade de Manaus oferece Unidades de Terapia Intensiva, o que reflete a falta de infraestrutura para atendimento de emergência de alta complexidade no interior da Amazônia. Mais que 20\% da população nos estados do Amazonas, Pará e Mato Grosso, dependem por até quatro horas para chegar ao município mais próximo com condições para atender casos graves de COVID-19. Especialmente as cidades menores, se afetadas simultaneamente pela fumaça de queimação e infecções pelo coronavírus, tendem a não apoiar as demandas da população (AMAZONAS, 2020). 
Os ativistas temem que o aumento da atividade comercial na Amazônia também acarrete um risco maior de que pessoas de fora levem doenças contagiosas para as comunidades indígenas - incluindo o coronavírus.

Os estudos também sugerem uma ligação entre a exposição à poluição das partículas do ar e casos mais graves de coronavírus, além dos aumentos sazonais da malária e da dengue na Amazônia durante o verão. Tais intercorrências tendem a pressionar mais as regiões remotas onde é difícil encontrar leitos hospitalares. Alertou-se também que os riscos à saúde gerados pelos incêndios não se limitam à Amazônia (ARAGÃO et al., 2020).

As partículas dos incêndios florestais podem viajar para outras áreas, à medida que as cidades relaxam as normas de distanciamento social no Brasil sem vigilância, testes e rastreamento de contatos adequados, uma intensa temporada de incêndios pode ter consequências devastadoras para a saúde pública, com a perda desnecessária de muitas vidas e o aumento das desigualdades locais. Enquanto os olhos do mundo permanecem focados na pandemia, resta saber se a situação da Amazônia receberá a mesma atenção que em 2019. Por derradeiro, as duas circunstâncias se complementam e tornam o panorama mais adverso para se adequar políticas públicas vitais para a preservação da vida, da natureza e do planeta.

\section{CONSIDERAÇÕES FINAIS}

Conforme observado, a Amazônia encontra-se sob uma dupla epidemia: uma decorrente do surgimento do coronavírus, que se dissemina nas cidades e localidades rurais, aldeias indígenas e quilombolas com maior violência, em razão das faltas de políticas públicas no oferecimento de infraestrutura e medicamentos para os povos ribeirinhos e tradicionais, além da dificuldade de acesso devido à logística da região. A outra, decorrente do desmatamento que, em tempos de epidemia, onde a economia está mais arrefecida e todos têm seus olhares voltados para o coronavírus, os garimpeiros, madeireiros e grileiros aproveitam a falta de fiscalização e avançam em um desmatamento criminoso da Amazônia. 
Com este artigo, abordou-se uma temática ainda pouco estudada, porém de notável discussão, a qual buscou alertar sobre as consequências para a saúde da população amazônica, da perigosa combinação de fumaça de queimadas decorrentes do desmatamento com a pandemia de COVID-19, e também indicar que os planos de emergência implementados pelos governos locais devem ser redimensionados adequando-se a particularidade socioambiental de cada região.

O prognóstico para os próximos meses é grave. Portanto, torna-se de caráter urgente que os governos federal, estaduais e municipais coordenem ações e estratégias para prevenir a vasta área já desmatada na Amazônia, e que está próxima de ser consumida por chamas.

O custo da inação pelas autoridades públicas não será medido pelo dano na biodiversidade e mudanças climáticas, mas pelas vidas humanas perdidas. Ações estruturadas são imprescindíveis para a eficiente redução do desmatamento e dos incêndios ilegais.

É perigoso que o governo brasileiro desconsidere a saúde da floresta amazônica. Há muitas evidências de que o crescimento econômico não precisa vir à custa do meio ambiente e, de fato, as pesquisas sugerem que as energias renováveis podem de fato estimular o crescimento econômico pós-COVID-19. É imperativo ainda que os líderes globais continuem pressionando o governo brasileiro a fazer mais no combate ao desmatamento, ou a saúde do planeta estará em risco.

Imperioso, por fim, que sejam direcionadas políticas de governo para oferecer serviços médicos e medicamentos aos povos ribeirinhos, indígenas e quilombolas, a fim de evitar o alastramento da doença e, quem sabe, até a dizimação de determinadas etnias, mas, ao mesmo tempo, torna-se imperioso o não negligenciamento da fiscalização contra o desmatamento praticado por garimpeiros, madeireiros e grileiros, dando efetividade à legislação ambiental existente, para se evitar uma dupla epidemia na Amazônia que refletirá no mundo todo. 


\section{REFERÊNCIAS BIBLIOGRÁFICAS}

ALENCAR, A. et al. Amazônia em Chamas - onde está o fogo: Nota Técnica no 2. Brasília: Instituto de Pesquisa Ambiental da Amazônia, 2019. Disponível em: https://ipam.org.br/bibliotecas/ amazonia-em-chamas-onde-esta-o-fogo/ . Acesso em: 20 jun. 2020.

AMAZONAS. Fundação de Vigilância Sanitária. Painel COVID-19 Amazonas (2020). Disponível em: http://saude.am.gov.br/painel/corona/. Acesso em: 13 jun. 2020.

ANDRADE, D. C. Economia e meio ambiente: aspectos teóricos e metodológicos nas visões neoclássica e da economia ecológica. Leituras de Economia Política, Campinas, v. 14, n. 1, p. 1-31, ago.-dez. 2008.

ARAGÃO, L. E. O. C.; SILVA JUNIOR, C. H. L.; ANDERSON, L. O. . O desafio do Brasil para conter o desmatamento e as queimadas na Amazônia durante a pandemia por COVID-19 em 2020: implicações ambientais, sociais e sua governança. São José dos Campos, 34p. 2020. SEI/ INPE: 01340.004481/2020-96/5543324. doi: 10.13140/RG.2.2.11908.76167/1.

ARRAES, R. A.; MARIANO, F. Z.; SIMONASSI, A. G. Causas do desmatamento no Brasil e seu ordenamento no contexto mundial. Rev. Econ. Sociol. Rural, Piracicaba-SP, v. 50, n. 1, p. 119-140, jan-mar/2012.

BARCELLOS, C. et al. Queimadas na Amazônia e seus impactos na saúde: A incidência de doenças respiratórias no sul da Amazônia aumentou significativamente nos últimos meses. $3^{\circ}$ Informe técnico do Observatório de Clima e Saúde. Fiocruz. (2019). Disponível em: https://climaesaude. icict.fiocruz.br/sites/climaesaude.icict.fiocruz. br/files/informe_observatorio_queimadas.pdf. Acesso em: 20 jun. 2020.

BRASIL, TERRABRASILIS. Taxas de desmatamento na Amazônia Legal (2019). Disponível em:

http://terrabrasilis.dpi.inpe.br/app/dashboard/deforestation/dashboard/deforestation/biomes/le gal_amazon/rates. Acesso em: 23 jun. 2020.

Painel Coronavírus. (2020). Disponível em: https://covid.saude.gov.br/. Acesso em: 10 jun. 2020.

CAVALCANTI, C. Concepções da economia ecológica: suas relações com a economia dominante e a economia ambiental. Estud. av., São Paulo, v. 24, n. 68, p. 53-67, 2010 .

COIAB 2020. Covid-19 e os povos indígenas na Amazônia Brasileira. Informativo Coiab 25/05/2020. Disponível em: https://coiab.org.br/conteudo/1590444906544x317059499264835600. Acesso em: 20 jun. 2020.

CONSTANTINO, K. P. Regularização fundiária sustentável: a necessidade de uma visão urbano-ambiental. Revista Estudos de Planejamento, n. 14, v. 1, p. 33-55, dez./ 2019. 
ELLWANGER, J. H. et al. Beyond diversity loss and climate change: Impacts of Amazon deforestation on infectious diseases and public health. An Acad Bras Cienc., v. 92, n. 1, p. 2933 , apr./2020.

FIOCRUZ. Regiões e Redes Covid-19: Acesso aos serviços de saúde e fluxo de deslocamento de pacientes em busca de internação. Nota técnica 5, 20 de maio de 2020. Disponível em: https://bigdata-covid19.icict.fiocruz.br/nota_tecnica_7.pdf. Acesso em: 17 jun. 2020.

IPAM. Instituto de Pesquisa Ambiental da Amazônia. 2020. Brasil: custos ambientais para a Amazônia . Belém, Brasil. Disponível em: www.ipam.org.br. Acesso em: 25 jun. 2020.

MACHADO-SILVA, F. et al. Drought and fires influence the respiratory diseases hospitalizations in the Amazon. Ecological Indicators. v. 109, n. 1, p. 1-13, oct./2020.

MARQUES, J. R. Sustentabilidade e temas fundamentais de Direito Ambiental. Campinas: Millenium Editora, 2009.

MAY, P. Economia do Meio ambiente: teoria e prática. 2. Ed. Rio de Janeiro: Elsevier, 2010.

MELO, A. W.F. et al. Monitoramento da qualidade do ar em 2019 no Estado do Acre. Cruzeiro do Sul: UFAC, 28 p. doi: 10.13140/RG.2.2.17584.10244.

MONTIBELLER, G. et al. Economia Ecológica e Sustentabilidade Socioambiental. Revista Brasileira de Ciências Ambientais, n. 23, p. 25-35, mar./ 2012.

MOUTINHO, P. Desmatamento na Amazônia: desafios para reduzir as emissões brasileiras. Org. Fundação Brasileira para o Desenvolvimento Sustentável. Rio de Janeiro: FBDS, 2019.

MOUTINHO, P. et al. The Amazon in flames deforestation and fire during the covid-19 pandemic. IPAM Amazônia, Nota Técnica, n. 4, 2020.

SAUER, S.; ALMEIDA, W. Terras e Territórios na Amazônia: demandas, desafios e perspectivas. Brasília: Editora Universidade de Brasília, 2011.

SILVÉRIO, D. et al. Amazônia em Chamas. Nota Técnica. $\mathrm{n}^{\circ}$ 1. Instituto de Pesquisa Ambiental da Amazônia. (2019). Disponível em: https://ipam.org.br/ bibliotecas/nota-tecnica-amazoniaem-chamas/. Acesso em: 20 jun. 2020.

SOARES-FILHO, B.S. et al. Modelling conservation in the Amazon basin. Nature, v. 440, n. 1, p. 520-523, 2006.

SOUZA, S. M. et al. Teor de óleo em cultivares de soja visando a produção de biocombustível no estado do Tocantins. Revista Desafios - Suplemento, mar./2020

VATN, A. What ecological economics needs to advance. In: ESEE (Ed.). 1996-2016 Anniversary Bulletin: Reflections on two decades of Ecological Economics in Europe, 2016. 
VIANA, R.L.; FREITAS, C.M.; GIATTI, L.L. Environmental health and development in legal amazon: socioeconomic, environmental and sanitary indicators, challenges and perspectives. Saúde Soc., v. 25, n. 1, p. 233-246, 2016.

Data de Submissão: 10/08/2020

Data de Aceite: 14/11/2020 